\title{
Behavioral Response of Lasioderma serricorne to Materials from Cinnamomum camphora
}

\author{
LYU Jianhua* , ZENG Shujing, HUO Mingfei, ZHANG Yupu, KANG Yulong
}

Engineering Research Center of Grain Storage and Security, Ministry of Education; School of Food Science and Technology, Henan University of Technology, Zhengzhou 450001, China

\begin{abstract}
The attractiveness of Cinnamomum camphora (Laurales: Lauraceae) blocks and essential oil to Lasioderma serricorne (Fabricius) (Coleoptera: Anobiidae) adults was investigated. The results showed that the behavioral response values of $L$. serricorne adults to $C$. camphora blocks significantly increased with increasing doses above the dose of $0.8 \mathrm{~g}$. The highest behavioral response values of $L$. serricorne adults were $93.33 \%$ to $C$. camphora blocks and $81.67 \%$ to $C$. camphora essential oil, respectively. $C$. camphora blocks had stronger attractiveness to L. serricorne adults than $C$. camphora oil. These results demonstrate that the effectiveness to control L. serricorne in practice of $C$. camphora blocks and $C$. camphora oil deserve to be further investigated.
\end{abstract}

Keywords: Attractive potential; Lasioderma serricorne; Cinnamomum camphora; Volatiles

\section{Introduction}

Insects often prefer to some special substances that can be used to manipulate insect behavior, particularly for insect monitoring and detecting programs. Many researches showed that the stored product insects could be apparently attracted by the volatiles from stored products or processed foods. For example, Tribolium castaneum (Coleoptera: Tenebrionidae ${ }^{[1]}$, Sitophilus granarius (Coleoptera: Dryophthoridae) ${ }^{[2]}$, T. confusum (Coleoptera: Tenebrionidae) $)^{[3]}$, Sitophilus zeamais (Coleoptera: Curculionidae ${ }^{[4]}$, Ahasverus advena (Coleoptera: Cucujidae) ${ }^{[5]}$, Sitophilus oryzae (Coleoptera: Curculionidae) ${ }^{[6]}$, and Oryzaephilus surinamensis (Coleoptera: Silvanidae) ${ }^{[7]}$ preferentially respond to the volatiles from cereal grains, and processed products.

The cigarette beetle, Lasioderma serricorne (Fabricius) (Coleoptera: Anobiidae) ranks as one of the most destructive pest insects of stored products worldwide ${ }^{[8]}$. Repeated and intensive use of phosphine for decades has resulted in serious negative issues including insecticide resistance, insect resurgence, insecticide residue, environment contamination, and lethal effects on non-target organisms ${ }^{[9]}$. Development and application of environment-friendly and sustainable control strategies has been considered to be the only effective method to cope with the increasing Cinnamomum camphora (Laurales: Lauraceae), commonly known as camphor tree, camphor laurel or camphorwood, originates in China, Japan, Korea, and Vietnam, and has been introduced to many other countries. The components of volatiles from $C$. camphora essential oil

Received: 2 December 2017 /Accepted: 2 April 2018.

Supported by National Program on Key R \& D Project (No. 2017YFC1600804), Key Technologies R \& D Program of the Education Department of Henan Province (No. 16A210017), and Province Key Laboratory of Transformation and Utilization of Cereal Resource, Henan University of Technology.

*Corresponding author. E-mail: jianhlv@163.com

CHenan University of Technology 2018

LYU J H, ZENG S J, HUO M F, et al. Behavioral Response of Lasioderma serricorne to Materials from Cinnamomum camphora[J]. Grain \& Oil Science and Technology, 2018, 1(2): 109-112. mainly include camphor, nerolidol, linalool, 1,8-cineole, safrole or borneol. Camphor has been used for many centuries as a kind of culinary spice, a component of incense, and medicine. The essential oil could be prepared from $C$. camphora wood and leaves by simultaneous distillation extraction method, which is often used by field workers to avoid insect biting in China during harvesting period ${ }^{[10]}$. However, little is known about the behavioral response of $L$. serricorne adults to the volatiles from $C$. camphora so far. Therefore, this study aims to evaluate the behavioral response of $L$. serricorne adults to $C$. camphora blocks and $C$. camphora essential oil in laboratory.

\section{Materials and methods}

\subsection{Insects}

Cultures of the cigarette beetle, L. serricorne, were maintained in the laboratory without exposure to any insecticide in the Institute of Stored Product Insects of Henan University of Technology, China. They were reared on sterilized diet (wheat feed/yeast, 95:5, $W: W)$ at $(27 \pm 2){ }^{\circ} \mathrm{C}, 75 \% \pm 5 \%$ relative humidity, and a 12:12 light:dark photoperiod. Healthy, unsexed 3 -d-old adults were randomly chosen for bioassays.

\subsection{C. camphora Blocks and C. camphora Essential Oil}

C. camphora blocks and C. camphora essential oil (purity 98\%) was purchased from Jishui Natural Essential Oil Industry Ltd., China. The specification of one $C$. camphora block (Wuyuan, China) is $2.5 \mathrm{~cm}$ (length) $\times 2 \mathrm{~cm}$ (width) $\times 2 \mathrm{~mm}$ (thickness). C. camphora blocks and $C$. camphora essential oil were respectively prepared form fresh branches and leaves.

\subsection{Analysis of . camphora Essential Oil}

The $C$. camphora essential oil was analyzed using a Shimadzu GC-MS QP2010 (Shimadzu, Kyoto, Japan) fitted with a fused silica DB-5MS $(30 \mathrm{~m} \times 0.25 \mathrm{~mm}$ i.d., $0.25 \mu \mathrm{m}$ film thickness) capillary column with helium as carrier gas. Temperature was programmed initially at $60{ }^{\circ} \mathrm{C}$ for $2 \mathrm{~min}$, and then increased at a rate of $10^{\circ} \mathrm{C} / \mathrm{min}$ to $280{ }^{\circ} \mathrm{C} / \mathrm{min}$, then 
maintained for $5 \mathrm{~min}$. The interface temperature was $250^{\circ} \mathrm{C}$. Injection was in unsplit mode. The MS was operated in the EI mode at $70 \mathrm{eV}$. The chromatograph was coupled to a Shimadzu QP5000 mass selective detector - EIMS (Shimadzu, Kyoto, Japan) at $70 \mathrm{eV}$. Identification of components was made by comparing their relative retention indices and mass spectra with those of authentic samples or those found in the literature, and the amount of the component was determined by the percentage of its peak area of total peak area ${ }^{[11]}$. NIST 11 and NIST 11s Library of Mass Spectra were used for identifying the compounds.

\subsection{Bioassay Procedure}

The behavioral response of $L$. serricorne adults to C. camphora blocks and C. camphora essential oil evaluated by using a two-choice pitfall bioassay was similar to that described by Germinara et al. ${ }^{[12]}$.

The test arena was a white round sheet iron barrel $(22 \mathrm{~cm}$ in diameter by $25 \mathrm{~cm}$ high) with two diametrically opposed holes ( $3 \mathrm{~cm}$ in diameter) $2.5 \mathrm{~cm}$ from the side wall. Two petri dishes ( $6 \mathrm{~cm}$ in diameter by $1.2 \mathrm{~cm}$ high) were positioned under each hole to collect responding insects. The petri dish wall and upside brim of the arena were coated with polyfluortetraethylene to avoid insects escaping. The tested $C$. camphora blocks and C. camphora essential oil were laid at the center of petri dish. 20 L. serricorne adults were kept in a petri dish $(6 \mathrm{~cm}$ in diameter by $1.2 \mathrm{~cm} \mathrm{high)} \mathrm{at} \mathrm{the} \mathrm{center} \mathrm{of} \mathrm{the} \mathrm{test} \mathrm{arena} \mathrm{and} \mathrm{allowed} 20 \mathrm{~min}$ to acclimatize the test environment prior to release. The test arena was covered with a piece of black cotton cloth tightly tied with a band at the upper edge to prevent insects from escaping. The bioassays were carried out in dark at $(27 \pm 2){ }^{\circ} \mathrm{C}$, and $75 \% \pm 5 \%$ relative humidity. C. camphora blocks were tested with doses of $0.4,0.6,0.8,1.0,2.0$, and $3.0 \mathrm{~g}$, and C. camphora essential oil was tested with doses of $0.05,0.2,0.4,0.6,0.8$, and $1.0 \mathrm{~mL}$. Each collecting petri dish was covered by a piece of Whatman No.1 filter paper ( $6 \mathrm{~cm}$ in diameter) on the inside bottom. A specific tested dose of $C$. camphora blocks was put on the filter paper in one petri dish, or a specific tested dose of $C$. camphora essential oil was evenly sprayed on the filter paper as a treatment. The filter paper in the other petri dish was treated nothing as a control. Each experiment was replicated four times. The number of insects present in the control $\left(N_{\mathrm{c}}\right)$ and treated $\left(N_{\mathrm{t}}\right)$ dishes was counted after 24,48 , and $72 \mathrm{~h}$ of exposure, respectively. The behavioral response values (BRV) of $L$. serricorne adults to $C$. camphora blocks or C. camphora essential oil were calculated as follows ${ }^{[13]}$ :

$$
\mathrm{BRV}=\left[\left(N_{\mathrm{t}}-N_{\mathrm{c}}\right) /\left(N_{\mathrm{c}}+N_{\mathrm{t}}\right)\right] \times 100 \%
$$

\subsection{Statistical Analysis}

The behavioral response values of $L$. serricorne adults to $C$. camphora blocks or C. camphora essential oil were determined and transformed to arcsine square-root values before subjecting to two-way analysis of variance (ANOVA) with BRVs as response variable, and dose, and exposure time as fixed effects. The mean BRVs were compared and separated by Scheffe's test at $P=0.05$. These analysis were performed using SPSS version 16.0 software.

\section{Results}

\subsection{Components of $C$. camphora Essential Oil}

The components of $C$. camphora essential oil are listed in Table 1. The main components of $C$. camphora essential oil included myrcene, terpinolene, $p$-cymene, 1,8-cinede, linalool, isoborned, (1R,4R)-(+)-camphor, terpinen-4-ol, $\alpha$-terpineol, safrole.

Table 1 Composition from $C$. camphora essential oil

\begin{tabular}{|c|c|c|c|}
\hline No. & Component & Structural formula & Amount (\%) \\
\hline 1 & myrcene & & 1.01 \\
\hline 2 & terpinolene & & 0.34 \\
\hline 3 & $p$-cymene & & 0.89 \\
\hline 4 & 1,8-cinede & & 28.19 \\
\hline 5 & linalool & & 0.56 \\
\hline 6 & $(1 \mathrm{R}, 4 \mathrm{R})-(+)$-camphor & & 52.91 \\
\hline 7 & D-Isoborneol & & 0.58 \\
\hline 8 & terpinen-4-ol & & 2.33 \\
\hline 9 & $\alpha$-terpineol & & 6.06 \\
\hline 10 & safrole & & 7.13 \\
\hline
\end{tabular}

\subsection{Behavioral Response of L. serricorne Adults to} C. camphora Blocks

L. serricorne adults had significantly different behavioral responses to $C$. camphora blocks $(F=13.25, \mathrm{~d} f=5,36$, $P<0.001)$ and $C$. camphora essential oil at different tested doses $(F=2.71, \mathrm{~d} f=5,36, P<0.001)$. C. camphora blocks showed strong attractive potential during the whole test period (Table 2). The behavioral response values of $L$. serricorne adults to $C$. camphora blocks significantly increased with increasing doses when tested at above $0.8 \mathrm{~g}$ of blocks, and the highest behavioral response values were 93.33, 86.67, and $86.67 \%$ after 24,48 , and $72 \mathrm{~h}$ of exposure, respectively.

\subsection{Behavioral Response of $L$. serricorne Adults to C. camphora Essential Oil}

C. camphora essential oil exhibited the strongest attractive potential to $L$. serricorne adults when tested at $0.6 \mathrm{~mL}$. The highest behavioral response values of $L$. serricorne adults to $C$. camphora essential oil were respectively $78.33 \%, 80.00 \%$, and $81.67 \%$ after 24,48 , and $72 \mathrm{~h}$ of exposure to $0.6 \mathrm{~mL}$ of C. camphora essential oil, respectively (Table 3). C. camphora blocks had stronger attractive potential to $L$. serricorne adults than C. camphora essential oil.

\section{Discussion}

The results indicate that both $C$. camphora essential oil and blocks have stronger attractiveness to $L$. serricorne adults. The 
Table 2 The behavioral response values of L. serricorne adults to C. camphora blocks \%

\begin{tabular}{cccc}
\hline $\begin{array}{c}\text { Dose } \\
(\mathrm{g})\end{array}$ & \multicolumn{3}{c}{ Observation time } \\
\cline { 2 - 4 } & $24 \mathrm{~h}$ & $48 \mathrm{~h}$ & $72 \mathrm{~h}$ \\
0.4 & $73.33 \pm 1.67^{\mathrm{Abcd}}$ & $71.67 \pm 3.33^{\mathrm{Aab}}$ & $46.67 \pm 3.33^{\mathrm{Bb}}$ \\
0.6 & $70.00 \pm 0.00^{\mathrm{Acd}}$ & $68.33 \pm 10.14^{\mathrm{Aab}}$ & $71.67 \pm 9.28^{\mathrm{Aa}}$ \\
0.8 & $56.67 \pm 4.41^{\mathrm{Ad}}$ & $56.67 \pm 4.41^{\mathrm{Ab}}$ & $65.00 \pm 7.64^{\mathrm{Aab}}$ \\
1.0 & $88.30 \pm 4.41^{\mathrm{Aab}}$ & $78.33 \pm 4.41^{\mathrm{Aab}}$ & $83.33 \pm 3.33^{\mathrm{Aa}}$ \\
3.0 & $80.00 \pm 10.41^{\mathrm{Aabc}}$ & $76.67 \pm 11.67^{\mathrm{Aab}}$ & $86.67 \pm 8.34^{\mathrm{Aa}}$ \\
& $93.33 \pm 3.33^{\mathrm{Aa}}$ & $86.67 \pm 6.01^{\mathrm{Aa}}$ & $86.67 \pm 8.33^{\mathrm{Aa}}$
\end{tabular}

Note: Data is Means \pm SD of four replicates. Different lowercases indicate significant differences in the same column, and different capital letters indicate significant difference in the same row $(P<0.05)$. The same as Table 3.

Table 3 The behavioral response values of $L$. serricorne adults to $C$. camphora essential oil \%

\begin{tabular}{cccc}
\hline $\begin{array}{c}\text { Dose } \\
(\mathrm{mL})\end{array}$ & \multicolumn{3}{c}{ Exposure time } \\
\cline { 2 - 4 } & $24 \mathrm{~h}$ & $48 \mathrm{~h}$ & $72 \mathrm{~h}$ \\
\hline 0.05 & $38.33 \pm 6.01^{\mathrm{Ac}}$ & $43.33 \pm 6.01^{\mathrm{Abc}}$ & $40.00 \pm 7.64^{\mathrm{Acd}}$ \\
0.2 & $61.67 \pm 8.33^{\mathrm{Aab}}$ & $61.67 \pm 3.33^{\mathrm{Aab}}$ & $71.67 \pm 1.67^{\mathrm{Aab}}$ \\
0.4 & $50.00 \pm 2.89^{\mathrm{Abc}}$ & $58.33 \pm 4.41^{\mathrm{Aab}}$ & $56.67 \pm 4.41^{\mathrm{Abc}}$ \\
0.6 & $78.33 \pm 3.33^{\mathrm{Aa}}$ & $80.00 \pm 7.64^{\mathrm{Aa}}$ & $81.67 \pm 6.01^{\mathrm{Aa}}$ \\
0.8 & $33.33 \pm 4.41^{\mathrm{Ac}}$ & $35.00 \pm 5.00^{\mathrm{Ac}}$ & $31.67 \pm 6.01^{\mathrm{Ad}}$ \\
1.0 & $65.00 \pm 11.55^{\mathrm{Aab}}$ & $65.00 \pm 11.55^{\mathrm{Aab}}$ & $63.33 \pm 13.02^{\mathrm{Aabc}}$ \\
\hline
\end{tabular}

behavior response of insects to volatiles depends on various factors, including insect species, developmental stage, dose, compound formulation, application method and special environmental condition, and so forth. Some compounds that strongly attract insects, specially sex pheromones, have been developed as attractants for detecting and monitoring programs ${ }^{[14-15]}$, or as attracticides $^{[16]}$.

The $C$. camphora essential oil, prepared by steam distilled method from $C$. camphora wood and leaves, is often used by field workers during harvesting seasons to avoid insects (mostly the mosquitoes) biting in China ${ }^{[10]}$. Camphor, a white crystalline substance, obtained from $C$. camphora tree, has been used for many centuries as a common culinary spice, a component of incense, and as a traditional medicine. Meanwhile, camphor is also a common insect repellent and a flea-killing substance. However, in the present research, C. camphora blocks and $C$. camphora essential oil could apparently attract L. serricorne adults. These demonstrate that different insect species differently response to the same chemical substance. The response mechanism of $L$. serricorne adults to $C$. camphora blocks and $C$. camphora essential oil needs to be further investigated, and the response of different developmental stages of $L$. serricorne to $C$. camphora blocks and $C$. camphora essential oil also should be studied.

This research results show that $C$. camphora blocks and $C$. camphora essential oil had potent potential as an attractant for controlling $L$. serricorne. The proper formulation, main components, dose, reasonable application strategy and environmental effect deserve to be researched, so that they can be exploited for effectively preventing disinfestation by L. Serricorne in practice in the future.

\section{Conflict of Interest}

The authors declare that there is no conflict of interest.

\section{References}

[1] CAMPBELL J F. Attraction of walking Tribolium castaneum adults to traps[J]. Journal of Stored Products Research, 2012, 51: 11-22.

[2] GERMINARA G S, De CRISTOFARO A, ROTUNDO G. Bioactivity of short-chain aliphatic ketones against adults of the granary weevil, Sitophilus granarius (L.)[J]. Pest Management Science, 2012, 68: 371-377.

[3] ATHANASSIOU C G, KAVALLIERATOS N G, TREMATERRA P. Responses of Sitophilus oryzae (Coleoptera: Curculionidae) and Tribolium confusum (Coleoptera: Tenebrionidae) to traps baited with pheromones and food volatiles[J]. European Journal of Entomology, 2006, 103: 371-378.

[4] TREMATERRA P, IANIRO R, ATHANASSIOU C G, et al. Behavioral responses of Sitophilus zeamais Motschulsky adults to conditioned grain kernels[J]. Journal of Stored Products Research, 2013, 53: 77-81.

[5] WAKEFIELD M E, BRYNING G P, COLLINS L E, et al. Identification of attractive components of carob volatiles for the foreign grain beetle, Ahasverus advena (Waltl) (Coleoptera: Cucujidae)[J]. Journal of Stored Products Research, 2005, 41: 239-253.

[6] KUMAR P P, MOHAN S, BALASUBRAMANIAN G. Effect of whole-pea flour and a protein-rich fraction as repellents against stored-product insects[J]. Journal of Stored Products Research, 2004, 40: 547-552.

[7] MOWERY S V, CAMPBELL J F, Mullen M A, et al. Response of Oryzaephilus surinamensis (Coleoptera: Silvanidae) to food odor emanating through consumer packaging films[J]. Environmental Entomology, 2004, 33: 75-80.

[8] KIM S, PARK C, OHH M H, et al. Contact and fumigant activity of aromatic plant extracts and essential oils against Lasioderma serricorne (Coleoptera: Anobiidae)[J]. Journal of Stored Products Research, 2003, 39: 11-19.

[9] JOVANOVIC Z, KOSTIC M, POPOVIC Z. Grain-protective properties of herbal extracts against the bean weevil Acanthoscelides obtectus Say[J]. Industrial Crops and Products, 2007, 26: 100-104.

[10] HIROTA N, HIROR M.The later studies on the camphor tree, on the leaf oil of each practical form and its utilisation[J]. Perfumery and Essential Oil Record, 1967, 58: 364-367.

[11] ASAWALAM E F, EMOSAIRUE S O, HASSANALI A. Bioactivity 
of Xylopia aetiopia (Dunal) A. Rich essential oil constituents on maize weevil Sitophilus zeamais Motschulsky (Coleoptera: Curculionidae)[J]. Electronic Journal of Environmental, Agricultural and Food Chemistry, 2006, 5: 1195-1204.

[12] GERMINARA G S, ROTUNDO G, DE CRISTOFARO A Repellence and fumigant toxicity of propionic acid against adults of Sitophilus granarius (L.) and S. oryzae (L.)[J]. Journal of Stored Products Research, 2007, 43: 229-233.

[13] LÜ J H, LIU S L. The behavioral response of Lasioderma serricorne (Coleoptera: Anobiidae) to citronellal, citral, and rutin[J]. SpringerPlus, 2016, 5(1): 798.
[14] TREMATERRA P. Advances in the use of pheromones for stored-product protection[J]. Journal of Pest Science, 2012, 85: 285-299.

[15] BURKHOLDER W E, MA M. Pheromones for monitoring and control of stored-product insects[J]. Annual Review of Entomology, 1985, 30: 257-272.

[16] NANSEN C, PHILLIPS T W. Attractancy and toxicity of an attracticide for Indianmeal moth, Plodia interpunctella (Lepidoptera: Pyralidae)[J]. Journal of Economic Entomology, 2004, 97(2): 703-710. 